\title{
periferio
}

\section{O LUGAR DA ORALIDADE NO ESPAÇO DA ESCRITA: DESAFIOS PARA EDUCAÇÃO ESCOLAR INDÍGENA GUARANI MBYA - RJ}

\author{
Gabriela Nunes Fernandes ${ }^{1}$ \\ Universidade do Estado do Rio de Janeiro - UERJ \\ Kelly Cristina Russo de Souza ${ }^{2}$ \\ Universidade do Estado do Rio de Janeiro - UERJ
}

\section{Resumo}

Este artigo discute a relação entre oralidade e escrita na educação escolar indígena a partir da perspectiva de uma professora Guarani, que atua há mais de dez anos na educação escolar de seu povo. Trata-se de uma pesquisa qualitativa e os instrumentos metodológicos foram: levantamento bibliográfico, observação participante em encontros de formação de professores Guarani e realização de entrevista. De acordo com as análises realizadas é possível considerar que os desafios em torno da oralidade e da escrita no contexto da educação escolar indígena precisam ser compreendidos como uma tensão intercultural permanente centrada nas reflexões e práticas de professores indígenas.

Palavras-chave: educação escolar indígena; oralidade e escrita; professor/a indígena

\footnotetext{
1 Graduada em Pedagogia pela Universidade do Estado do Rio de Janeiro, Faculdade de Educação da Baixada Fluminense (UERJ-FEBF). gabi.n.fernandes93@gmail.com

2 Professora Adjunta da Universidade do Estado do Rio de Janeiro. Faculdade de Educação da Baixada Fluminense - Departamento de Formação de Professores. UERJ-FEBF-DFF Doutora em Educação Brasileira pela Pontifícia Universidade Católica do Rio de Janeiro - PUC-RJ. Mestre em Ciências Sociais e Educação pela Faculdade Latino-Americana de Ciências Sociais, FLACSO, Argentina. Graduação em Comunicação Social Jornalismo. Universidade do Estado do Rio de Janeiro, UERJ - kellyrussobr@gmail.com
}

Periferia, v. 10, n. 2, p. 21-43, jul./dez. 2018

DOI: 10.12957/periferia.2018.33191 


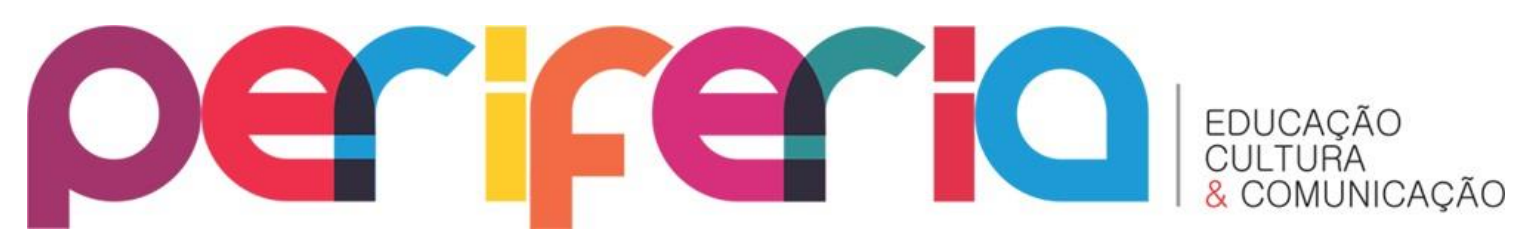

\title{
THE PLACE OF ORALCY IN THE SPACE OF WRITING: CHALLENGES FOR INDIGENOUS SCHOOL EDUCATION GUARANI MBYA - RJ
}

\begin{abstract}
This article discusses the relationship between orality and writing in indigenous school education from the perspective of a Guarani teacher, who has been working for more than ten years in the school education of her people. It is a qualitative research and the methodological instruments were: bibliographic survey, participant observation in meetings of training of Guarani teachers and interviewing. According to the analyzes carried out, it is possible to consider that the challenges regarding orality and writing in the context of indigenous school education need to be understood as a permanent intercultural tension and that the leading role of indigenous teachers should be a central concern.
\end{abstract}

Keywords: indigenous school education; oral and written teaching; indigenous teacher 


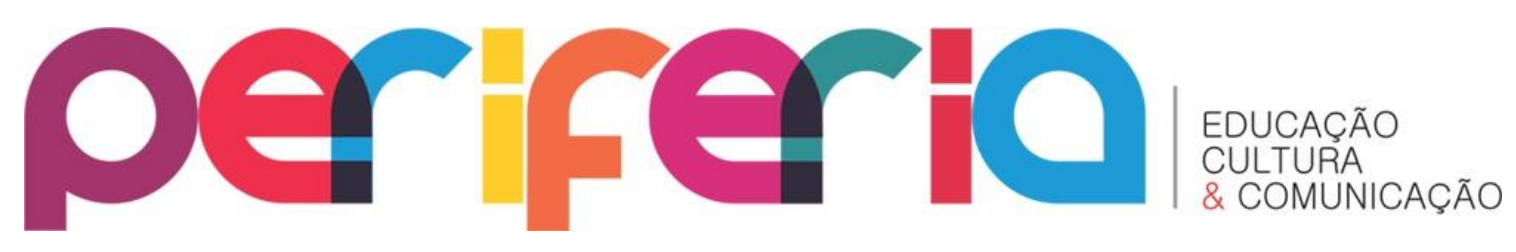

\section{O POVO GUARANI-MBYA E A PEDAGOGIA GUARANI}

O povo Guarani é um dos maiores grupos indígenas da América do Sul e no Brasil representam quase $9 \%$ do total de indígenas existentes em território nacional (Funasa, 2010). No Rio de Janeiro, os Guarani Mbya estão distribuídos em terras situadas no litoral do estado, em área de Mata Atlântica, e possuem interação regular e crescente com as pequenas e médias cidades ao redor das aldeias. Nas aldeias vivem cerca de 600 índios Guarani do subgrupo Mbya e, em menor quantidade, Ñandeva (Funasa, 2010).

A maior parte dessa população vive da venda de artesanatos ou pela realização de trabalhos pontuais e esporádicos realizados nas cidades vizinhas. Outras fontes importantes de renda surgem a partir dos contratos de trabalho relacionados aos serviços nas áreas da educação e saúde nessas aldeias ou através de programas sociais do Governo Federal, como aposentadoria rural ou bolsa família ${ }^{3}$.

Nesta parte introdutória do texto, apresentamos algumas informações mais gerais sobre o povo Guarani Mbya que habita o estado do Rio de Janeiro.

\section{Quem são os Guarani Mbya}

Acreditamos ser oportuno abrir esse subcapítulo utilizando a denominação de Bergamaschi (2007) para a população guarani: caminhante! Entretanto, ao fazermos isso, não iremos simplesmente delimitar algumas de suas características, pois, procuraremos historicizar os Guarani Mbya na tentativa de compreender as demandas que se apresentam no contexto atual e perspectivas de vida, segundo o nhandereko em língua guarani (palavra que os guarani utilizam para dizer "jeito de ser guarani").

Há tempos os Guarani andam por caminhos diversos, trilhados pelo vasto território da Mata Atlântica, desde o litoral do Brasil às florestas no leste

\footnotetext{
${ }^{3}$ Bolsa Família (programa de transferência direta de renda que beneficia famílias com renda per capita inferior a 77 reais mensais) e Aposentadoria Rural (benefício concedido pelo Instituto Nacional do Seguro Social, Ministério da Previdência Social, para agricultores acima dos 55 anos).
}

Periferia, v. 10, n. 2, p. 21-43, jul./dez. 2018

DOI: $10.12957 /$ periferia.2018.33191 


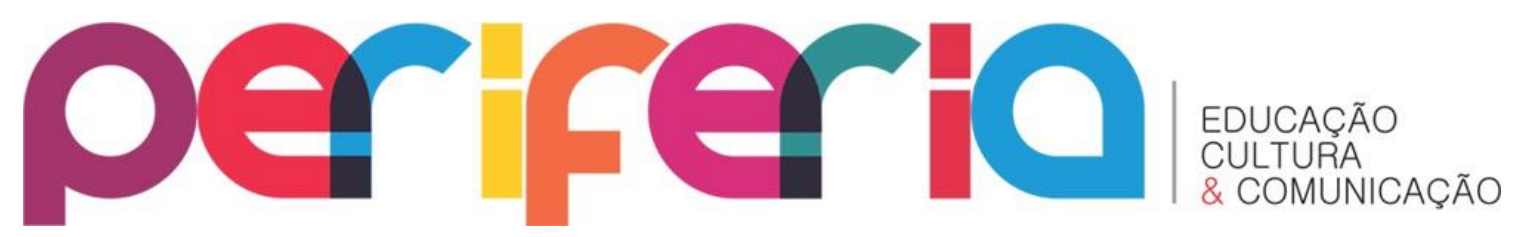

paraguaio. No Rio de Janeiro, a população guarani vive em áreas mbya denominadas Aldeia Sapukai, na região de Bracuhy, Angra dos Reis, a maior do Rio de Janeiro, Parati Mirim de nome Itaxi, de Araponga, e em Paraty nas aldeias Saco de Mamanguá e Rio Pequeno. Há, ainda, caminhantes Guarani em Maricá, na Aldeia Mata Verde Bonita (Ka'aguy Hovy Porã) e, recém-chegados em Itaipuaçu, advindos do Espírito Santo.

Bergamaschi (2007) afirma que devido ao processo de colonização, a privatização da terra tem provocado uma espécie de fragmentação territorial, inclusive a retirada do primeiro bem dos povos habitantes da América. Com os Guarani não foi diferente. No entanto, a luta secular pela manutenção de um espaço que thes garanta viver dignamente é cada vez mais intensa tendo em vista o estreitamento da relação que estabelecem com sociedades não indígenas e a relação de poder que as mesmas exercem sobre os povos indígenas.

As disputas constantes por território marcam a história dos Guarani, sobretudo porque a terra é um dos elementos centrais na configuração desse povo, na qual mantém uma relação de vida e cuidado extremamente difícil de ser compreendida, do ponto de vista da cosmologia ocidental moderna, baseadas na propriedade, exterioridade e pragmatismo (BERGAMASCHI, 2007). A efeito disso, a população Guarani têm diminuído drasticamente, contabilizando apenas 35 mil indígenas em todo território brasileiro (ISA, 2000). Número alarmante se comparados à população guarani colonial, que representavam milhões.

Foram séculos de contato com colonizadores que, segundo Nobre (2005), teria produzido efeitos irreversíveis como a diminuição demográfica, o aprisionamento territorial, as crises políticas internas de liderança e o suposto impacto das missões sobre a religião e religiosidade dos Guarani. Desse modo, é possível problematizar, ainda, à historiografia referente à formação do Brasil meridional no período colonial que consta duas tendências reducionistas sobre os povos indígenas, que conforme Monteiro (1992) apud Nobre (2005), ora são dominados, amansados e catequizados, ora dizimados e escravizados. Sendo assim, pouco é explorada as estratégias que os povos indígenas, 


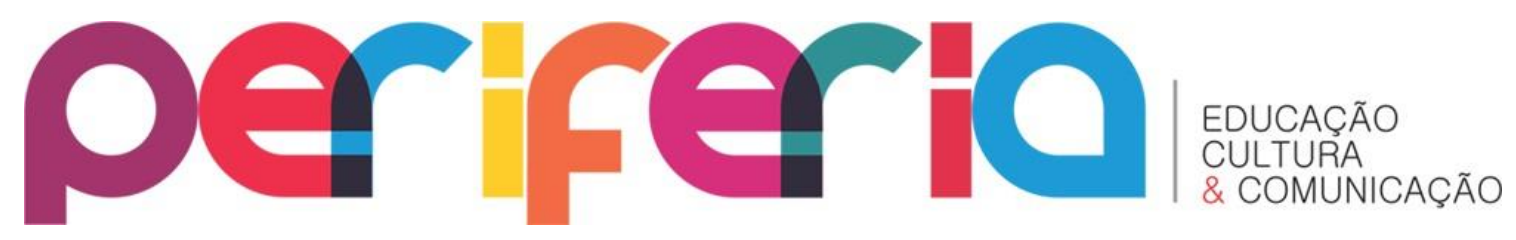

especificamente, os Guarani Mbya, (re)criam para manutenção e ressignificação do "modo de ser guarani".

Para Bergamaschi (2005) apesar da educação tradicional indígena, baseada na cosmologia Guarani, sustentar suficientemente o modo de ser/viver guarani, a escola torna-se uma ferramenta necessária para desenvolver saberes que se relacionam à escola - tais como a leitura, a escrita, a Língua Portuguesa, o sistema monetário, entre outros - e, nesse sentido, os guarani afirmam o desejo de se apropriar de instrumentos que permitam o diálogo equitativo com sociedades não indígenas. Para esta pesquisa me detenho às experiências da professora e pedagoga indígena Guarani Sandra Benites com as comunidades Guarani Mbya no Estado do Rio de Janeiro, mais especificamente das aldeias Sapukai, em Angra dos Reis, que abriga cerca de 379 habitantes, Tekoa Ka'aguy Hovy Porã e Itaipuaçu, localizadas em Maricá, que abrigam, respectivamente, 40 e 28 habitantes.

\section{Pedagogia Guarani: revendo a educação escolar a partir da perspectiva Guarani}

Conforme define Pissolato (2007), o movimento, para os Guarani, é o que fornece condições de vida consideradas boas: é a expressão de uma maneira própria de configurar o território, para além da demarcação da terra indígena estabelecida pelo Estado, em um vasto circuito de espaços nos quais ocorre intensa circulação, tanto de pessoas como de plantas, matérias-primas, sementes, informações. A correlação e as redes de parentesco e de reciprocidade que esse povo mantém através de relações políticas, matrimoniais, religiosas e econômicas são cruciais para o fortalecimento desse grupo.

Dessa maneira, os Guarani recriam continuamente as situações que thes são impostas a partir de uma intensa rede de trocas e de fluxos populacionais entre as aldeias. Em relação à educação escolar, autores como Bergamaschi (2007 e 2012) e Nobre (1996, 2002, 2005 e 2009) indicam que existe um modo próprio de ensinar, que está em diálogo com os princípios que compõem a 


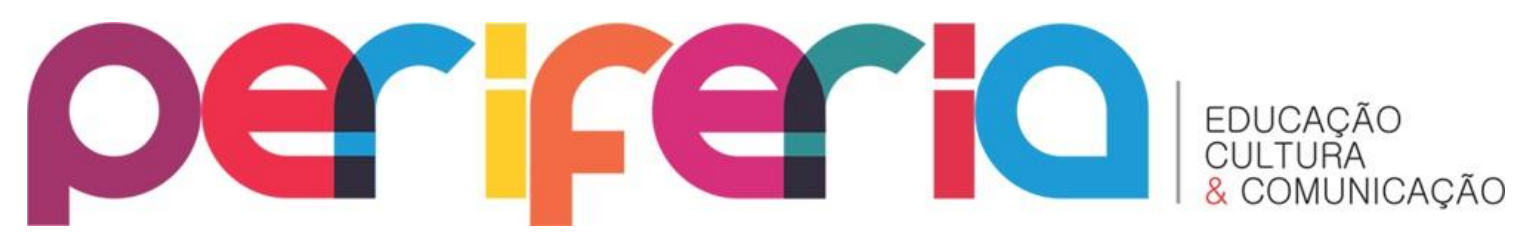

educação tradicional e a cosmologia desse povo. Nesse sentido, procuraremos apresentar aqui alguns dos elementos que compõe a Pedagogia Guarani, segundo esses autores:

1) Autonomia, Liberdade e Descontração das Crianças: Existe uma grande liberdade exercida pelas crianças guarani que não são repreendidas em quase nada. São advertidas somente quando o caso é de segurança física, ou se estiver prejudicando muito a proposta do professor, o que é incomum. As crianças possuem bastante autonomia em relação às suas decisões, como a de sair da sala, por exemplo, se a proposta do professor não estiver atrativa.

2) Forte participação das Crianças: Durante as atividades, as crianças movimentam-se, falam, auxiliam o colega, de maneira produtiva. Tratase de uma participação descompromissada, interessada somente no conhecimento novo que a aula proporciona.

3) Grande curiosidade e observação: A curiosidade é uma característica que aparece com frequência na rotina de crianças indígenas, sobretudo, quando se deparam com algo pertencente a outro universo cultural. A criança guarani observa com atenção as falas, os gestos, o comportamento dos seus interlocutores e o faz muito ativamente. o lugar privilegiado ocupado pela criança guarani faz com que ela se torne participante de todas as situações cotidianas, o que permite-a estar diante de qualquer conversa ou cena, sem proibição.

4) Língua Guarani como língua de instrução: Bilinguismo de manutenção e resistência: Em uma aula Guarani a língua de instrução é o Guarani. As crianças só conversam em Guarani entre si, o que garante espaço adequado de uso social da língua materna com status sociolinguístico.

5) Forte presença da oralidade com certo desapego à escrita: $O$ povo Guarani é milenarmente oral. A língua Guarani foi traduzida pela linguagem escrita pelos jesuítas, após a invasão. Sendo assim, a oralidade garante presença nas aulas seja nas explicações, nas conversas, nos exemplos, nas histórias. É possível observar, ainda, um desapego pelos papéis e pelo que eles 


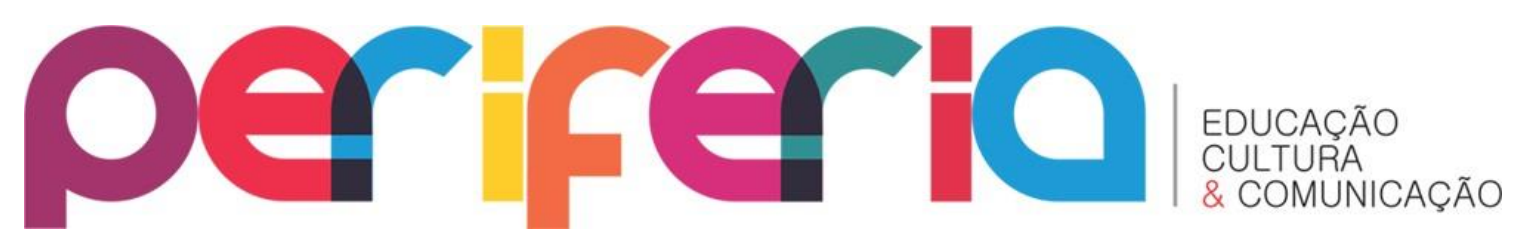

representam. O papel grafado circula pela aldeia de maneira difusa, imprecisa, temporária, não sistemática e irregular.

6) Necessidade de preservação da cultura; o nhadereko: Como sabem que são detentores de uma cultura milenar que precisa ser mantida, os professores se esforçam para desenvolver em suas aulas temáticas, histórias, atividades, brincadeiras que são do universo cultural tradicional indígena guarani, de acordo com o projeto político pedagógico.

7) Presença de ritual e formalismo nas aulas: Os Guarani valorizam os elementos simbólicos que compõe a aula: o quadro, as carteiras, as canetas, os lápis coloridos. Organizam-se em fileiras, de frente para o professor. Raramente modificam a organização das carteiras e dificilmente as colocam em círculos. Importante destacar o papel social exercido pelo professor e o grande respeito de todos por esta liderança.

8) Ocorrência de imitação: Os mais velhos exercem papel fundamental na cultura Guarani e na educação indígena. Nas aulas, as crianças costumam reproduzir o que os professores estão fazendo, do mesmo modo que as crianças menores imitam as crianças maiores no cotidiano de brincadeiras da aldeia.

9) Ocorrência de repetição nas atividades: A repetição é uma técnica significativa no processo educacional indígena, pois a oralidade é permeada de repetições, sendo marca da linguagem produzida por esse povo. A repetição é central na educação social, e busca a clareza, a simplicidade, a síntese, o essencial.

10) Grande respeito mútuo nas relações: Existe um enorme respeito que permeia as relações escolares entre alunos e professores guarani. 0 respeito mútuo pode ser compreendido como fruto da educação tradicional indígena guarani, ou seja, o/a professor/a, além de ser considerado/a liderança, é mais velho em relação às crianças e os jovens da comunidade.

11) Grande ocorrência de desenhos nas atividades; Além da linguagem oral, existe outra linguagem bastante apreciada pelos Guarani: o desenho. Nota-se que, em geral, os Guarani são excelentes pintores e desenhistas. 


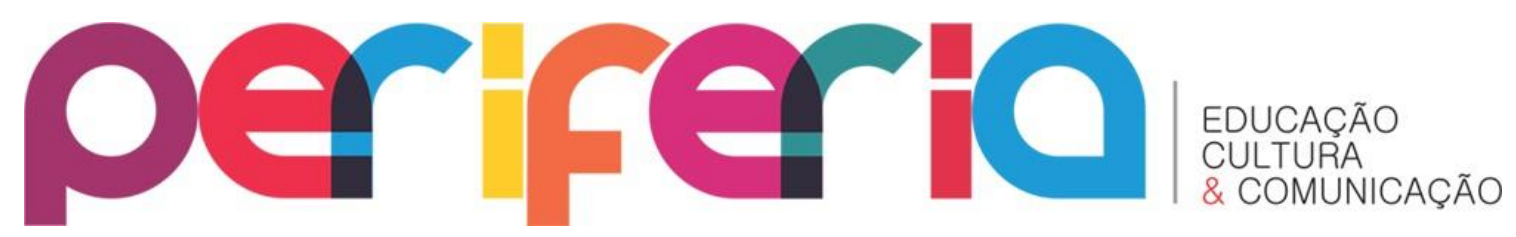

0 artesanato produzido por este povo é muito colorido e o padrão estético formal é detalhista e complexo. Os professores frequentemente recorrem ao desenho em suas aulas, bem como incentivam suas crianças a desenharem. As aulas dos professores nem sempre são reproduzidas com base na pedagogia tradicional não indígena. Constata-se professores Guarani incorporam e recriam elementos característicos da pedagogia escolar não indígena de forma criativa ao longo de suas aulas, assim como colocam elementos da educação tradicional indígena nas relações pedagógicas da sala de aula. ${ }^{4}$

Como indicado por Bergamaschi:

Mesmo sabendo não serem suas as práticas escolares, mas agregadas da cosmologia ocidental, ali na aldeia, longe da intervenção dos juruá, fagocitam essa escola e constroem formas próprias de ensinar a aprender: Intuem a necessidade de aprender com o coração e deixam extravasar os sentimentos ternos que aproximam as pessoas no respeito às individualidades que faz cada pessoa viver sua autonomia na convivência coletiva. Praticam a observação e a imitação como poder de projetar e criar caminhos próprios, fazendo da repetição um ato criativo, seguindo a dinâmica da oralidade. A curiosidade, que movimenta cada um na busca, pulula, junto à criança que procurou a escola pelo seu interesse e mostra isso na vivacidade com que se envolve na atividade proposta realizando-a de modo particular. (...). O que a prática da escola na aldeia Guarani sugere é que, no fazer, a tornam semelhante a si, pois mostram apropriar-se dela, guaranizando-a. (BERGAMASCHI, 2005, p. 228)

No contexto da educação escolar indígena nota-se a maneira como povo Guarani tem criado e recriado a escola, ao articular saberes tracionais aos saberes escolares, especialmente quando se trata da linguagem oral e da linguagem escrita, em exemplo nítido de contação de história e construção de desenho.

\footnotetext{
${ }^{4}$ Documentário - Uma aula Guarani ETE (Parte 1) Disponível em:
} https://www.youtube.com/watch?v=kh6cYinLLV4 


\section{periferio}

\section{ORALIDADE E ESCRITA: DESAFIOS PARA EDUCAÇÃO ESCOLAR INDÍGENA}

Com o intuito de refletir sobre a relação entre oralidade e escrita nos processos de ensino-aprendizagem dos Guarani, este capítulo se propõe a fundamentar teoricamente estas discussões a partir de autores que contribuíram com o tema em esfera nacional, como Monte (1996) e Testa (2007).

\section{Cultura oral $\mathrm{X}$ cultura escrita: uma revisão}

Para contextualizar a relação entre oralidade e escrita em contextos indígenas optamos por trazer teóricos, acompanhados de experiências empíricas que nos permitam compreender o processo de inserção da escrita em comunidades não letradas.

Entre o passado e o presente dos povos indígenas é possível identificar, através dos estudos de Monte (1996), que o meio de comunicação/expressão é, milenarmente, oral e há poucos anos a escrita é inserida, através das práticas escolares. Nesse sentido, é oportuno conceituar oralidade, cuja denominação abre caminhos diversos.

Segundo Ong (1998) apud Galvão (2006, p.407) há uma distinção entre “oralidade primária" e "oralidade secundária":

a primeira refere-se à oralidade das culturas intocadas pelo letramento ou por qualquer conhecimento da escrita ou da imprensa ou, ainda, a das pessoas totalmente não familiarizadas com a escrita. A segunda, por sua vez, refere-se à atual cultura de alta tecnologia, em que uma nova oralidade é sustentada pelo telefone, rádio, televisão e outros meios eletrônicos que, para existirem e funcionarem, dependem da escrita e da imprensa.

Zunthor (1993), apud Galvão (2006), distingue três tipos de oralidade. A primeira que, denomina "primária e imediata", não estabelece contato algum com a escrita. Em segundo lugar, haveria uma "oralidade mista", em que o oral e o escrito coexistem e, por fim, a "oralidade segunda", àquela que deriva de uma "cultura letrada". 


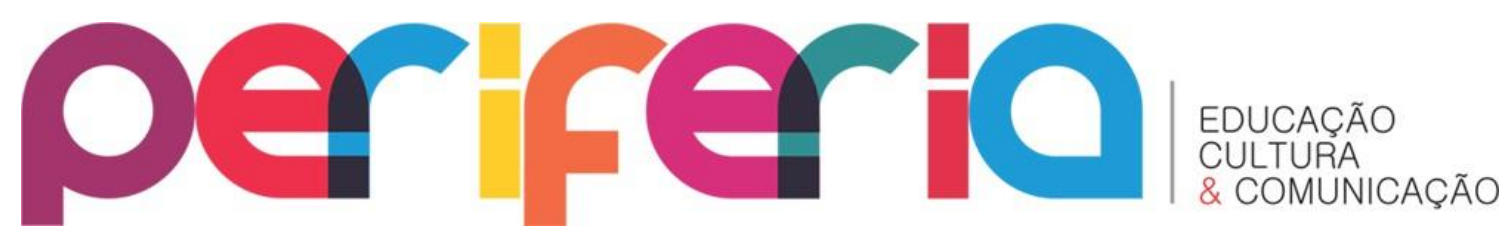

É preciso considerar ainda que as definições aqui apresentadas não pretendem estabelecer dicotomias entre sociedades orais e letradas, pelo contrário. De acordo com Ong (1998), na atualidade, não existe cultura de oralidade primária no sentido estrito, visto que a escrita está presente e provoca efeitos em todas as culturas.

Street (1988) apud Monte (1996) aponta para a oposição mecânica entre sociedades do tipo oral e letrada e afirma que, nos últimos duzentos anos, a maioria dos povos do mundo não vivem em nenhuma das duas situações exclusivamente, mas sim participa ativamente de outras culturas, influenciadas pela circulação da palavra escrita e/ou pela presença de indivíduos letrados.

No contexto dos povos indígenas é possível recorrer a autores que afirmam a necessidade de apropriação da escrita após o contato com o outro, letrado. Inicialmente, a alfabetização destinava-se a resoluções de problemas advindos dessa relação, no entanto a aquisição da escrita alia-se a processos de construção de práticas sociais peculiares. Testa (2007) sugere outras reflexões acerca da escrita, do ponto de vista dos Guarani Mbya que caminham no sentido contrário às afirmações de que a escrita é um registro da oralidade. A fala de Verá Mirim nos possibilita repensar as relações entre escrita e memória, na medida em que afirma "em vez de preservar a memória, a escrita se perde, enquanto as palavras suspiradas no interior de cada um e distribuídas coletivamente se mantêm nos caminhos de circular conhecimentos" (TESTA, 2007. p. 300).

Nesse contexto, é possível considerar que a palavra-falada-cantada possui estreita relação com a educação tradicional guarani e caracteriza-se como um elemento relevante para se pensar a educação escolar indígena.

Tensão, ambiguidade e contradição entre tradição oral e vontade de aquisição da escrita

A Pedagogia Guarani atenta para oralidade, como um elemento pedagógico da educação escolar indígena Guarani. No entanto, nos deparamos com conflitos e fronteiras que nos permitem uma reflexão acerca da aquisição 


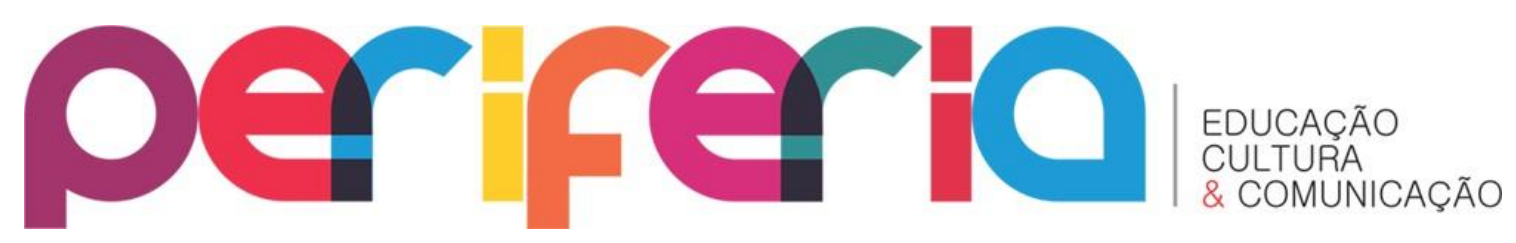

da escrita através da escola indígena. Neste momento, é oportuno remetermos à teoria de fricção interétnica na tentativa de compreender as relações marcadas pelo desequilíbrio de poder entre culturas (cultura Guarani e cultura que se impõe, proveniente da sociedade nacional).

As contradições do processo que envolve tradição oral e vontade de aquisição da escrita em sociedades indígenas não são recentes, e nem peculiar do povo Guarani. Monte (1996), a partir de experiências com o povo Kaxinawá do Rio Jordão, constatou que o contato com a escrita se deu a partir da produção econômica e trocas comerciais, onde muitas vezes os índios eram subordinados por patrões e seringueiros, tanto nos preços quanto nos pesos, por não dominarem o mundo letrado.

No que diz respeito ao povo Guarani Mbya do Rio de Janeiro, o domínio da escrita alfabética e numérica possui estreita relação com a principal atividade econômica: artesanato; vendidos nas cidades próximas às aldeias. $\mathrm{E}$ que muito tem a ver com a ideia dos índios roraimenses quando dizem que é importante entender o português para não serem enganados pelos não indígenas.

A iniciativa do professor indígena Algemiro da Silva, da aldeia Sapukai, de reunir crianças "embaixo de um pé de maracujá" desde 1996 para "ensinar a cultura dos brancos" é um exemplo nítido do que entendemos por interculturalidade que, segundo Candau (2011) "é a promoção deliberada da interrelação entre diferentes sujeitos e grupos socioculturais presentes em uma determinada sociedade" (CANDAU, 2011. p.247).

O Referencial Curricular Nacional para as Escolas Indígenas (RCNEI, 1998), por sua vez, afirma que aos processos educativos próprios das sociedades indígenas veio somar-se a experiência escolar com as várias formas e modalidades que assumiu ao longo da história do contato. Desse modo, os conflitos, as tensões e a ambiguidade entre tradição oral e aquisição da escrita podem ser entendidos como fruto da interculturalidade e das relações interétnicas estabelecidas entre os Guarani e a sociedade não indígena. 


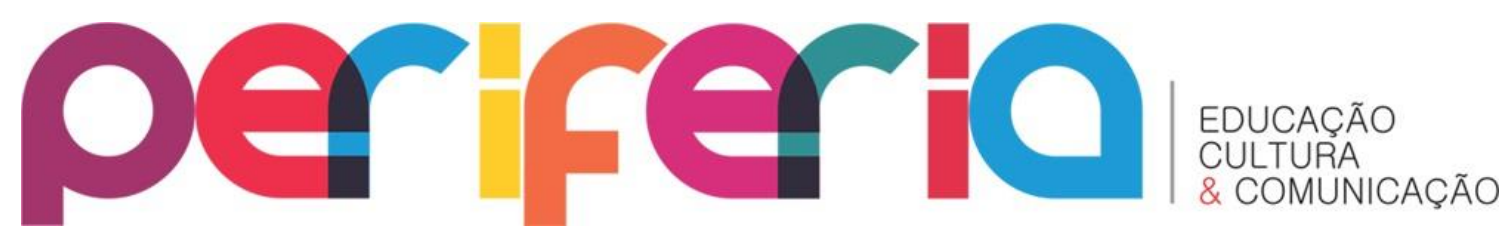

Patrimônio cultural imaterial, oralidade e interculturalidade: desafios na Educação Escolar Indígena

A Constituição Federal de 1988, nos artigos 215 e 216 estabeleceu que o patrimônio cultural brasileiro é formado de bens de natureza material e imaterial, incluindo os modos de criar, fazer e viver dos grupos que formam a sociedade nacional. A Convenção da UNESCO para a Salvaguarda do Patrimônio Cultural Imaterial, ratificada pelo Brasil em $1^{\circ}$ março de 2006 define como patrimônio imaterial:

As práticas, representantes, expressões, conhecimentos e técnicas - assim como os instrumentos e objetos, artefatos e espaços culturais que lhe são associados - que as comunidades, os grupos e, em alguns casos, indivíduos reconhecem como fazendo parte integrante de seu patrimônio cultural. Esse patrimônio cultural imaterial - que se transmite de geração em geração - é constantemente recriado pelas comunidades e grupos em função de seu entorno, de sua interação com a natureza e sua história, e lhes fornece um sentimento de identidade e de continuidade, contribuindo assim a promover 0 respeito pela diversidade cultural e a criatividade humana.

Neste sentido, a manifestação do patrimônio cultural imaterial acontece em particular nos âmbitos da dança, música e artes; das representações tradicionais, das práticas sociais, nos rituais e eventos festivos; dos conhecimentos e os usos relacionados à natureza e ao universo; das técnicas artesanais tradicionais e em especial das tradições e expressões orais, incluindo a língua como veículo do patrimônio cultural imaterial. A partir desse ponto de vista, a oralidade, assim como a língua guarani, é considerada patrimônio cultural imaterial do povo Guarani, e encontram-se intrinsecamente ligadas à educação, seja ela tradicional, ou escolar.

Conforme Sandra Benites (2015, p.20) defende em seu trabalho de conclusão de curso, os mais velhos são responsáveis pela transmissão de conhecimentos, ou seja:

Os mais velhos ensinam a eles [jovens] como fazer as coisas e os jovens começam a praticar esses saberes. É trabalhando que eles 


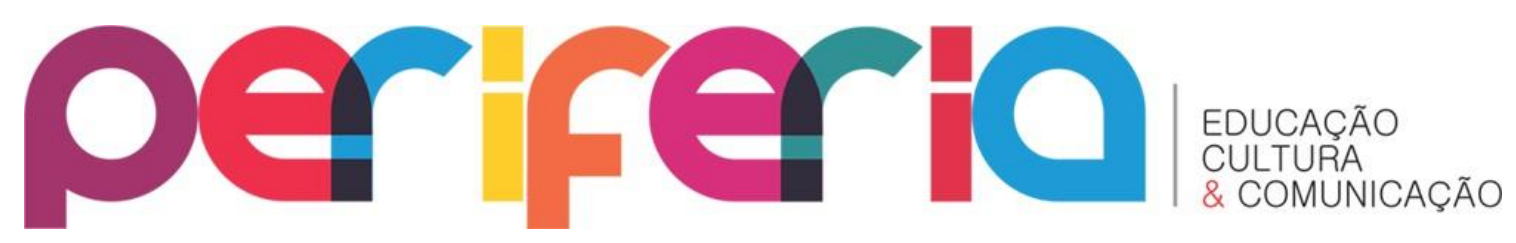

vão escutando as historias de vidas dos mais velhos, ouvem conselhos sobre vários assuntos: casamento, família, aprendem como tratar as mulheres, falam sobre bebidas, o que fazer quando tem filhos, etc. (BENITES, 2015. p. 20)

Desse modo, Sandra Benites nos ajuda a perceber a presença da oralidade na cultura tradicional Guarani e a importância da palavra dos mais velhos, seja na contação de histórias, nos conselhos, ou nos sonhos. Segundo a autora, são nessas horas que os mais velhos contam as histórias da origem do nhadereko ${ }^{5}$ e narram os mitos sagrados. "Os conselhos e conhecimentos são transmitidos na $o p y^{6}$, mas é trabalhando, praticando que eles aprendem" (p.20).

Posto isso, o desafio agora é refletir sobre como esses elementos deveriam estar presentes na educação intercultural pensada no contexto indígena. Bergamaschi (2007; 2012) e Nobre (1996; 2002; 2005; 2009) constatam que uma das características da Pedagogia Guarani se concentra na forte presença da oralidade e certo desapego à escrita, seja nas explicações, nas conversas, nos exemplos, ou nas histórias. Os diálogos curtos, conforme traz o Referencial Curricular Nacional para Escolas Indígenas (RCNEI, 1998), é uma alternativa de articular oralidade e escrita, na educação intercultural.

O desenho, também apontado por Nobre (2009), como uma das características da Pedagogia Guarani, proporciona interação entre as histórias que poderão ser contadas e posteriormente, registradas junto ao professor, como vimos no primeiro encontro para construção de materiais didáticos ${ }^{7}$ que reuniu professores indígenas Guarani das aldeias do Rio de Janeiro, em Itaipuaçu.

Neste sentido, nota-se uma relação estreita entre oralidade e diferentes formas de registros, não apenas os escritos, durante o desenvolvimento da educação escolar indígena. O desafio está em transformar o cotidiano escolar para que ele seja capaz de criar espaços de fortalecimento da língua materna,

\footnotetext{
${ }^{5}$ Nhadereko, em língua Guarani, é um termo utilizado para definir o "modo de ser Guarani".

6 Opy, também em língua Guarani, aproxima-se da ideia de "casa de reza".

${ }^{7}$ Encontro de professores indígenas, professores universitários e graduandos para construção de materiais didáticos Guarani, em Itaipuaçu.
}

Periferia, v. 10, n. 2, p. 21-43, jul./dez. 2018 


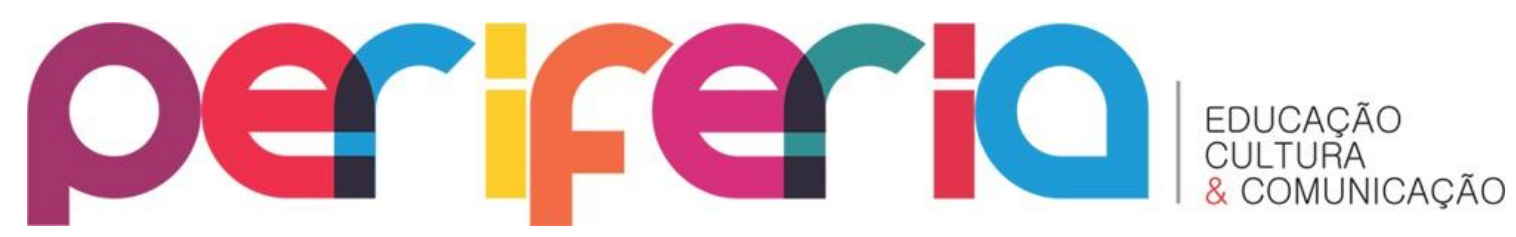

de forma a considerar a complexidade do universo Guarani, e ao mesmo tempo imprimir interpretações do cotidiano da comunidade, seja através do desenho, da contação de histórias, ou até mesmo da construção de texto.

\section{A ORALIDADE NA PRÁTICA PEDAGÓGICA DE UMA PROFESSORA GUARANI}

Para essa pesquisa, realizamos levantamento bibliográfico, observação participante em três encontros de formação de professores Guarani durante o mês de outubro de 2015, ocorridos na Aldeia Tekoa Ka'aguy Hovy Porã, em Maricá-RJ, além da realização de entrevista em profundidade com a professora Sandra Benites em junho de 2016. Essa entrevista seguiu um roteiro inicial préestabelecido, mas foi desenvolvida de modo aberto, permitindo que a própria entrevistada incluísse novos temas e tópicos para a nossa reflexão.

A partir de nossa conversa com a professora indígena, repensamos o conceito de escrita. De acordo com Harris (1980) apud Barros (1994, p.30) a tradição intelectual ocidental define a escrita como "[...] forma superior de expressão do conhecimento por ter eliminado as barreiras do tempo e da memória. Assim, um sistema de conhecimentos baseados na escrita, é considerado superior às formas de conhecimentos orais" (HARRIS, 1980 apud BARROS, 1994, p.30). Segundo o mesmo autor, outra característica é a de considerar a possibilidade de transpor com fidelidade os sistemas de conhecimento oral para a escrita.

No entanto, as contribuições da professora indígena Guarani acerca da palavra e da oralidade na cultura Guarani nos permite romper com afirmação de Harris, uma vez que "palavra sagrada a gente não consegue traduzir" (BENITES, 2016: comunicação pessoal). Ainda, segundo a professora, a oralidade é importante porque expressa "aquilo que a gente sente com o coração, o jeito de ser Guarani" (BENITES, 2016: comunicação pessoal). Nesse sentido, concordamos com Barros (1994) quando afirma que "a escrita científica só tem o poder de guardar resíduos da oralidade e não de reproduzi-la". (BARROS, 1994, p. 31). 


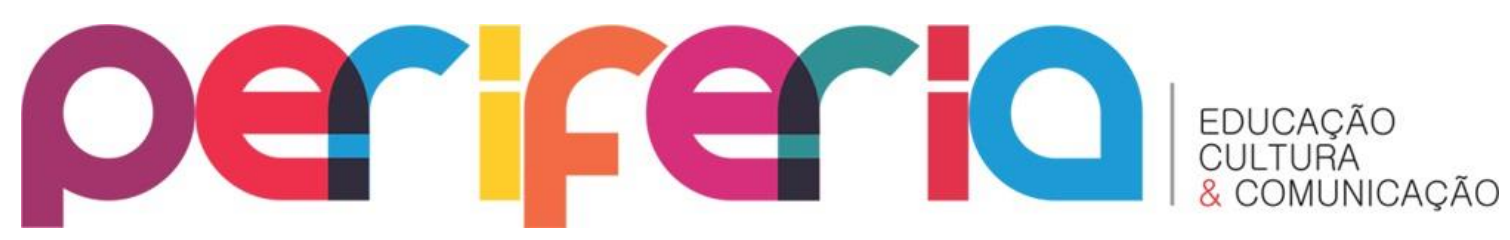

Nesse debate, a autora Maria Cândida Barros contribui para pensarmos as experiências da professora Guarani ao criar problematizações sobre como os mitos narrados oralmente a serem transcritos para o papel produzem uma ruptura em termos de domínio de saberes, pois "a publicação das narrativas tradicionais em forma de livro de leitura para a escola, acabam sendo de certas pessoas no grupo e não de todos: a sua difusão escrita na escola altera a forma de seu domínio ao separar o conhecimento do conhecedor" (BARROS, 1994, p. 32).

Para Sandra Benites (2016):

Através do canto, através da palavra sagrado que a gente [Guarani] se reúne, faz também ritual através da palavra sagrada, do canto que a gente faz o Nhemongarai e assim o encontro dos Guarani, onde a gente se junta pra gente cantar e dançar é tudo oralidade, então eu acho que isso tem muito a ver com nosso "jeito de ser Guarani", a questão da oralidade. (BENITES, 2016: comunicação pessoal)

Ladeira (2002) aponta as diferenças entre as competências orais e escritas e acredita que "é ilusão pensar que a oralidade e a escrita sejam dois caminhos possíveis para se transmitir as mesmas mensagens" (2002, p. 3). Nesta perspectiva, a professora Guarani sublinha que a questão da oralidade aparece, ainda, através da contação de histórias, no ritual do Nhemongarai ${ }^{8}$ na casa de reza, ou, no sepultamento de alguma pessoa que tenha falecido. As histórias são contadas sempre pelos mais velhos em forma de conselhos e afirma nunca ter visto seus parentes anotando, em forma de escrita.

Uma marca de registro do povo Guarani que permanece vivo é a pintura corporal e o objeto, como por exemplo, o maracá. Existem diferenças entre a pintura corporal para a menina e para o menino, em cada etapa da vida. Tem pinturas que representam proteção, para que nenhum mal se aproxime do corpo. Nas palavras de nossa entrevistada: “Essas pinturas são feitas com uma frutinha amarelinha, chamada djate'i, em Guarani, que tem mel, remédio e a cera que esquenta para fazer pintura. É utilizada também pra acender, como

\footnotetext{
${ }^{8}$ Nhemongarai, em língua guarani, é o ritual de batismo, uma cerimônia importante para o Povo Guarani, onde se recebem orientações espirituais.
}

Periferia, v. 10, n. 2, p. 21-43, jul./dez. 2018 


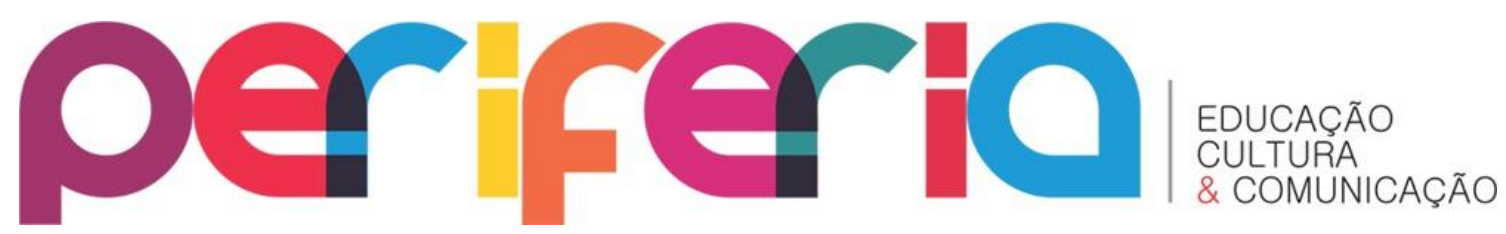

se fosse uma vela no batismo, pra fazer fumaça. Tem um cheiro muito gostoso." (BENITES, 2016: comunicação pessoal).

Ao considerar a pintura corporal como uma forma de escrita - não alfabética, mas bastante eficiente no registro histórico de cada comunidade e também de cada sujeito e seu lugar social nessas sociedades, pretendemos, no próximo subcapítulo, refletir um pouco mais sobre como a palavra, a oralidade e a escrita se articulam na educação intercultural indígena Guarani.

\section{Oralidade e escrita: experiências e desafios nessa articulação}

Na perspectiva de Sandra Benites, a articulação entre oralidade e escrita foi sempre um grande desafio em sua pratica docente:

Todos os trabalhos que eu vou começar a fazer eu costumo mesmo partir da avaliação dos alunos, por exemplo: 0 que eles querem? Eu sempre faço essa pergunta: E o quê eles esperam? 0 que eles querem? Como eles querem? Então, eu procuro saber, fazer esse levantamento todo pra poder começar. Então, pra mim, eu acho que a questão da oralidade, é sempre a partir da oralidade, o conhecimento que eles têm também, né, aproveitar o conhecimento que eles têm e a necessidade. [...] em Itaipuaçu, eu falei com as crianças como eles podem... [fs] como a gente estava discutindo sobre educação ambiental [fs], eles fizerem pergunta através do desenho, através da escrita, os que já sabiam escrever, escreviam, perguntam em Guarani mesmo, os que sabem falar em Português escreviam em Português e eu deixei assim à vontade e teve uns que fizeram pergunta através do desenho e eu achei muito interessante o que eles fizeram [...] (BENITES, 2016: comunicação pessoal)

Segundo a professora Guarani, cada um tem uma habilidade diferente e nesse sentido é preciso conhecer bem a comunidade, o contexto, identificar o que é específico.

$\mathrm{Na}$ verdade, o problema que eu identifiquei lá [em Itaipuaçu], como eles queriam trabalhar essa questão da sustentabilidade levando em consideração a respeito da cultura Guarani eu falei para as crianças o que é da cultura Guarani que não tem lá no local? [...] eles fizeram no papelzinho palmito que é djedy [em língua Guarani], aí eles colocaram aldeia cheia de batata doce, 


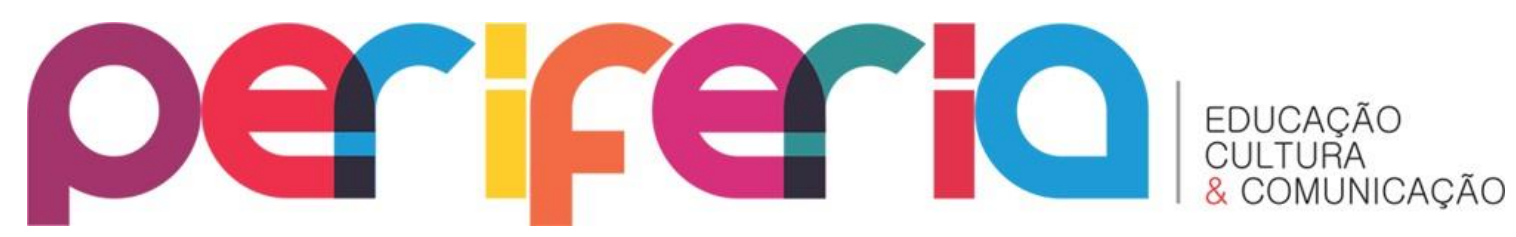

eles colocaram em torno da aldeia cheia de jabuticabeira, eles colocaram o pindo [em língua Guarani] que é palmeira, eles colocaram rio e cheio de peixe no rio e na beira do rio cheio de frutinha, aquele que a gente fala do, eu não sei como que chama em Português só sei que era guaporoity [em língua Guarani], guaporoity é uma frutinha bem docinha que cai tudo na água pra alimentar os peixinhos." (BENITES, 2016: comunicação pessoal)

A partir da experiência da professora Guarani é possível encontrarmos o conceito de patrimônio cultural imaterial atrelado à articulação da tradição oral à prática da escrita na educação intercultural. Para a nossa entrevistada, a oralidade fortalece o jeito de ser Guarani, a questão do costume Guarani.

A escrita pro Guarani, pra mim, seria aquela vivência, o jeito de ser Guarani que tem que ser uma reflexão do jeito de ser daquela comunidade. Só que muitas vezes a escola ela é confundida um pouco, porque muitas vezes a gente faz uma tradução pro Português do Guarani. Isso dificulta a gente também. Eu passei por isso, eu não entendia o que era. Hoje eu vejo muitos professores com dificuldade de fazer essa continuidade de oralidade repassa pra escrita que seria escever sobre reflexão da oralidade, da tradição Guarani. (BENITES, 2016: comunicação pessoal)

Nessa direção, a escrita, ou, o registro não deve se dar através da tradução. Nas palavras da professora, a escrita pode ajudar como interpretação daquela tradição e ela continua enfatizando que:

O conhecimento Guarani tem que ser registrado de uma forma mais... não escrita em forma de texto, mas em forma de vídeo, áudio. Eu acho assim, porque é tudo assim muito de canto, muita palavra sagrada, muito jeito de falar Guarani. Não tem como a gente escrever isso no papel e é uma coisa muito difícil isso. Acho que teria que registrar de uma forma mais verdadeira. (BENITES, 2016: comunicação pessoal)

De acordo com as Diretrizes para a Política Nacional de Educação Escolar Indígena (BRASIL, MEC, 1994), elaborado antes da Lei 9394 de 1996, fundamentado na Constituição Federal de 1988 as atividades propostas sob a perspectiva da educação intercultural devem considerar as diferentes finalidades sociais e culturais da linguagem escrita e oral, de modo que seu ponto de partida seja a língua que realmente existe, com ênfase na oralidade.

Periferia, v. 10, n. 2, p. 21-43, jul./dez. 2018 


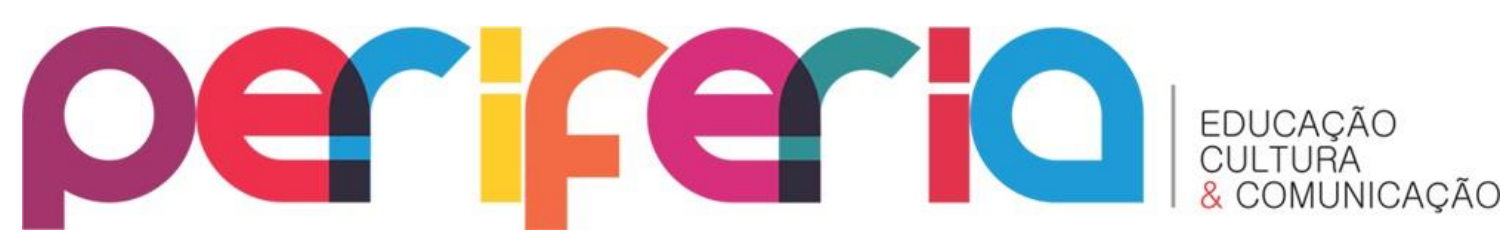

$\mathrm{Na}$ experiência da professora Guarani em questão é possível perceber alguns exemplos acerca da finalidade sociocultural da linguagem oral e escrita. Mas é importante considerar que os desafios e a construção em torno das práticas que articulam oralidade e escrita na educação escolar indígena Guarani são peculiares e varia de acordo com a comunidade. A professora Sandra Benites afirma que na aldeia Sapukai, por exemplo, as prioridades não são a busca do fortalecimento da identidade, do canto, porque a tradição Guarani está viva naquela comunidade. Nesse contexto, a questão do ensino da Língua Portuguesa era o maior desejo da comunidade, o que também facilitaria a abordagem da questão dos direitos indígenas, ou de textos relacionados à política interna e externa de alianças do grupo.

No caso das escolas nas aldeias situadas no Espírito Santo, a professora diz ter sentido muito mais necessidade de se falar sobre o "Sagrado", sobre como se constrói a identidade Guarani, todo o complexo mundo Guarani. "Com as crianças falar dos mais velhos, da tradição, outra dinâmica", explica a professora. Tendo em vista a diferença entre os grupos Guarani, entendemos que a sensibilidade intercultural deve ser colocada em questão. Quando se trata de uma comunidade onde a cultura e a tradição Guarani são evidenciadas em suas práticas sociais e culturais é possível, na escola, priorizar o diálogo entre as culturas, por exemplo, fazer a ligação da política Guarani com a política externa, isso requer leitura e escrita em Língua Portuguesa. Mas em contextos de maior fragilidade e vulnerabilidade cultural, a comunidade escolar precisa responder a demandas de fortalecimento identitários.

A professora Guarani inclui ainda, no debate intercultural, a necessidade de se compreender "que não é a cultura, é a política. Tem que ser discutida essa política dos juruá (não indígena) para que haja esse diálogo de fato, o que é importante pra mim, o que não é importante, o que pode se adaptar dentro da comunidade que é da política do juruá." (Benites, 2016: comunicação pessoal).

Assim, entendemos que o contexto deve ser colocado em questão para se pensar a educação escolar indígena, e sobretudo, a educação intercultural 


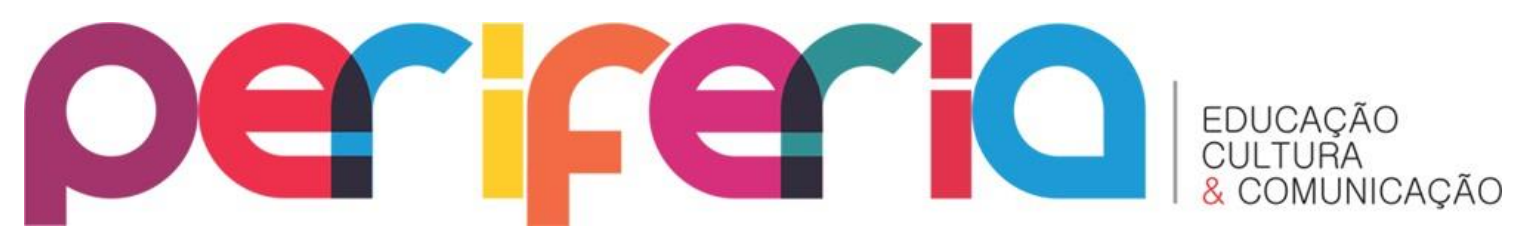

de forma que os Guarani utilizem destas trocas culturais para construírem juntos a escola que almejam:

O processo não linear e homogêneo, mas contraditório e multifacetado o que coincide com a contraditória relação do Guarani com a cultura não indígena; o que os faz adiar a opção pela escola, de resistir à sua ocidentalização completa ou construi-la de forma irregular e ambígua, guaranizando-a. (Trecho do documentário - Uma aula Guarani ETE parte 2, retirado do YouTube)

A oralidade e a escrita, nesse sentido, poderão ser aliadas à medida que a identidade étnica de um povo estiver fortalecida, não para traduzir elementos da cultura Guarani para a Língua Portuguesa, mas para uma melhor compreensão da política juruá no que tange aos direitos dos povos indígenas e seus interesses. Cabe ainda, nesta possível articulação, identificar o que querem, ou seja, qual a demanda da comunidade e, utilizarem a educação intercultural em busca de um diálogo mais equitativo com a sociedade nacional.

\section{CONSIDERAÇÕES FINAIS}

As análises realizadas neste trabalho foram frutos de discussões e questionamentos acerca do lugar da oralidade no espaço da escrita, assim como os desafios de articulação entre a educação tradicional Guarani e a prática da escrita na escola.

De acordo com as reflexões presentes nesta investigação é possível considerar que os desafios em torno da oralidade e da escrita no contexto escolar indígena possuem estreita relação com a preocupação da interculturalidade e o reconhecimento da identidade étnica da comunidade. Nesse sentido, é preciso conhecer o povo em questão e compreender suas reivindicações e professores indígenas possuem um espaço central nesse movimento de aproximação e reconhecimento étnico.

A educação intercultural é multifacetada, porque, ao mesmo tempo em que pode contribuir no tocante à garantia dos direitos dos povos indígenas, possibilita um encontro desigual de forças. A preocupação da escrita e a relação entre oralidade e o domínio da escrita precisa estar conectada com as questões 


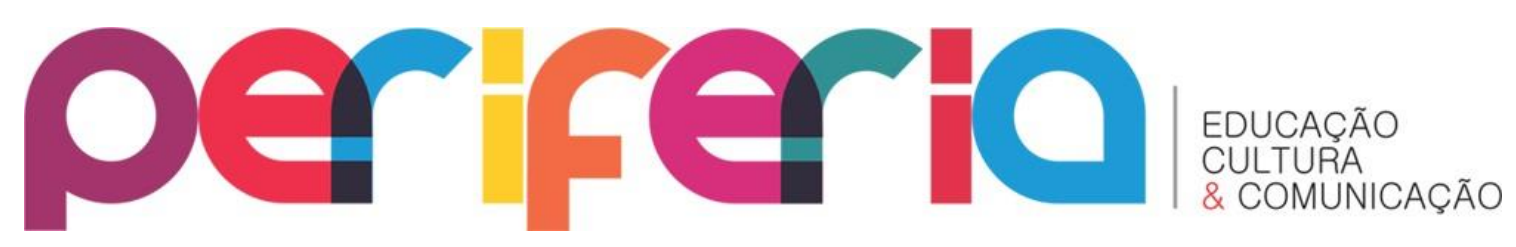

demandadas por esse povo. Talvez, esta relação precisa ser pensada para além do espaço escolar.

Ao reconhecer que a educação intercultural é multifacetada trata-se além da inserção da escrita nas escolas em contexto indígena, mas, sobretudo, discutir também os elementos da estrutura escolar que são inseridos no espaço escolar. A relação de desigualdade de poder existente entre culturas que convivem na escola, incluindo elementos considerados nocivos que passam a ser incorporados pela sociedade indígena a partir do contato com a sociedade nacional. Até que ponto a educação intercultural prejudica ou favorece as sociedades indígenas? Como identificar ou intervir os danos causados por essa interculturalidade que não discute as desigualdades de poder intrínsecas a essa relação?

Retomando às análises, consideramos possíveis as relações entre oralidade, escrita, patrimônio cultural imaterial e interculturalidade desde que não ameace a existência de um povo, e sim, que o fortaleça e o faça refletir sobre o dia-a-dia da comunidade, o modo de viver, fazer, pensar, e produzir existência.

\section{REFERÊNCIAS}

ALVARENGA, Márcia et al. Educação popular, movimentos sociais e formação de professores: outras questões, outros diálogos. EdUERJ: Rio De Janeiro, 2012.

BARROS, Maria Cândida Drumond Mendes. Educação Bilíngüe, Lingüística e Missionários. Em Aberto, v. 14, n. 63, p.18-37, jul./set., Brasília, 1994.

BENITES, Sandra. Nhe'ẽ, reko porã rã: nhemboea oexakarẽ Fundamento da pessoa guarani, nosso bem-estar futuro (educação tradicional): o olhar distorcido da escola. (Trabalho de conclusão de curso) UFSCAR - Licenciatura Intercultural Indígena do Sul da Mata Atlântica: Santa Catarina, 2015.

BERGAMASCHI, Maria Aparecida. Nhembo'e - enquanto o encanto permanece!: processos e práticas de escolarização nas aldeias Guarani. (Tese de doutorado). UFRGS/FACED Programa de Pós-Graduação em Educação: Rio Grande do Sul, 2005.

BERGAMASCHI, Maria Aparecida. Nhembo'e - educação escolar nas aldeias guarani. Pontifícia Universidade Católica de Rio Grande do Sul, Revista 


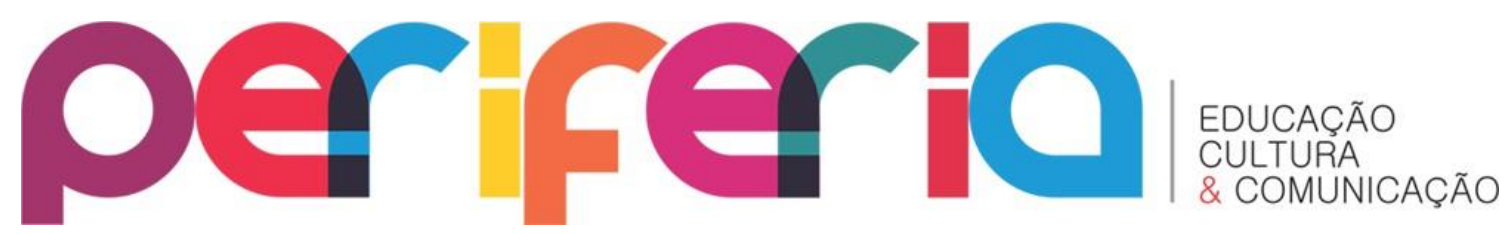

eletrônica: Rio Grande do Sul, 2007. Disponível em:

http://revistaseletronicas.pucrs.br/ojs/index.php/faced/article/viewFile/542 I378 Acesso em: março de 2018.

BRASIL, Constituição Federal, 1988.

BRASIL, Diretrizes para a política nacional de Educação Escolar Indígena, 1994.

BRASIL, Prefeitura Municipal de Maricá, 2015.

BRASIL, Presidência da República Casa Civil Subchefia para assuntos jurídicos. DECRETO N ${ }^{\circ}$ 5.753, DE 12 DE ABRIL DE 2006. Convenção da Unesco para a Salvaguarda do Patrimônio Cultural Imaterial, ratificada pelo Brasil em $1^{\circ}$ março de 2006.

BRASIL. Lei de Diretrizes e Bases da Educação Nacional. №. 9394/96. Brasília, 1996.

CANDAU, Vera Maria Ferrão. Diferenças Culturais, Cotidiano Escolar e Práticas Pedagógicas. Currículo sem Fronteiras, v.11, n.2. Pontifícia Universidade Católica do Rio de Janeiro: Rio de Janeiro, 2011. Disponível em: http://www.curriculosemfronteiras.org/vol11iss2articles/candau.pdf Acesso em: março de 2018.

$\mathrm{COHN}$, Clarice. Notas sobre a escolarização indígena no Brasil. Proposta programa de ações afirmativas para UFSCAR. DCSo/UFSCAR: Santa Catarina, 2006. Disponível em: http://www.acoesafirmativas.ufscar.br/arquivos/notassobre-a-escolarizacao-indigena-no-brasil-texto-de-clarice-cohn Acesso em: março de 2018.

GALLOIS, Dominique Tilkin et al. Patrimônio cultural imaterial e povos indígenas: exemplos no Amapá e norte do Pará. lépe: São Paulo, 2006. Disponível em:

https://www.institutoiepe.org.br/media/livros/livro_patrimonio_cultural_im aterial_e_povos_indigenas-baixa_resolucao.pdf Acesso em: março de 2018.

FRANCHETTO, Bruna. A guerra dos alfabetos: os povos indígenas na fronteira entre o oral e o escrito. PPGAS/UFRJ: Rio de Janeiro, 2007.

GALVÃO, Ana Maria de Oliveira; BATISTA, Antonio Augusto Gomes. Oralidade e escrita: uma revisão. Cadernos de Pesquisa, UFMG: Minas Gerais, 2006.

Disponível em: http://www.scielo.br/pdf/cp/v36n128/v36n128a07 Acesso em: março de 2018.

HARRIS, Roy. The language-makers. Duckworth: London,1980.

LADEIRA, Maria Elisa. Sobre a língua da Alfabetização Indígena. USP: São Paulo, 2002.

Periferia, v. 10, n. 2, p. 21-43, jul./dez. 2018

DOI: 10.12957/periferia.2018.33191 


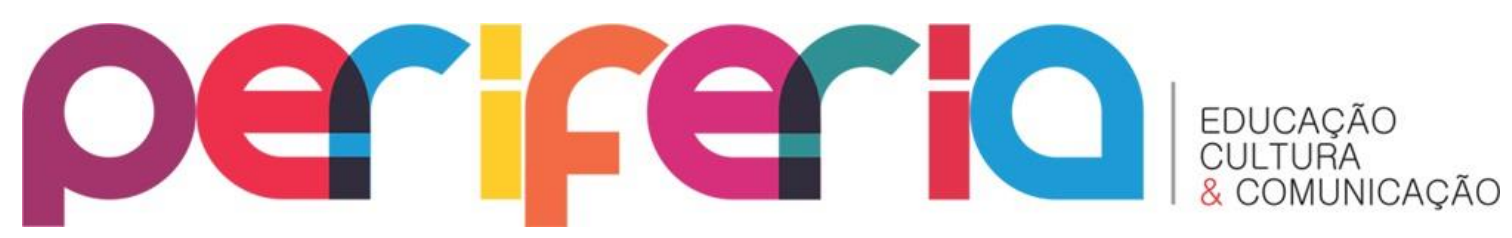

MEC. Referencial curricular nacional para as escolas indígenas/Ministério da Educação e do Desporto, Secretaria de Educação Fundamental. - MEC/SEF: Brasília, 1998.

MONTE, Nietta L. Escolas da Floresta: entre o passado oral e o presente letrado; diários de classe de professores Kaxinawá. Multiletra: Rio de Janeiro, 1996.

MONTEIRO, John Manuel. Os Guarani e a História do Brasil Meridional. Séculos XVIXVII. In: CARNEIRO DA CUNHA, Manuela.(Org.) História dos Índios no Brasil. Companhia das Letras: São Paulo, 1992.

NEVES, Josélia Gomes. Cultura escrita em contextos indígenas. UNESP: São Paulo, 2009. Disponível em: http: / / wwws.fclar.unesp.br/agendapos/educacao_escolar/1951.pdf Acesso em: março de 2018.

NEVES, Josélia Gomes. Alfabetização Intercultural: impactos da cultura escrita em sociedades ágrafas. Fundação Universidade Federal de Rondônia: Rondônia, 2008.

NOBRE, Domingos Barros. A História do Povo Guarani. UFF: Níterói, 2005.

NOBRE, Domingos Barros; ALENCAR, C. S; AZEVEDO, M. P; SILVA, T. O. Infancia Guarani Mbya: Andar e Ser Entre a Casa de Reza e a Escola. In: V Colóquio Internacional de Filosofia da Educação, 2010, Rio de Janeiro. "DevirCrianca da Filosofia: Infancia da Educação". UERJ: Rio de Janeiro, 2010.

NOBRE, Domingos Barros. Uma pedagogia indígena Guarani na escola, pra quê? Curt Nimuendaju: Rio de Janeiro, 2009.

NOBRE, Domingos Barros. Escola Indígena Guarani no Rio de Janeiro na Perspectiva da Autonomia: Sistematização de Uma Experiência de Formação Continuada. (Tese de Doutorado). Faculdade de Educação. UFF: Niterói, 2005.

NOBRE, Domingos Barros. Processos de Construção de Políticas em Educação Escolar Indígena no Estado do Rio de Janeiro. Minas Gerais: 24a Reunião Anual da ANPEd, 2001.

NOGUEIRA, Fernando do Amaral. Continuidade e Descontinuidade Administrativa em Governos Locais: fatores que sustentam a ação pública ao longo dos anos. (Dissertação de Mestrado). Escola de Administração de Empresas de São Paulo: São Paulo, 2006.

ONG, Walter. Orality and Literacy. Cambridge University Press: London, 1982.

PISSOLATO, Elizabeth de Paula. A duração da pessoa: mobilidade, parentesco e xamanismo mbya (guarani). UFRJ/MN/PPGAS: Rio de Janeiro, 2006. 


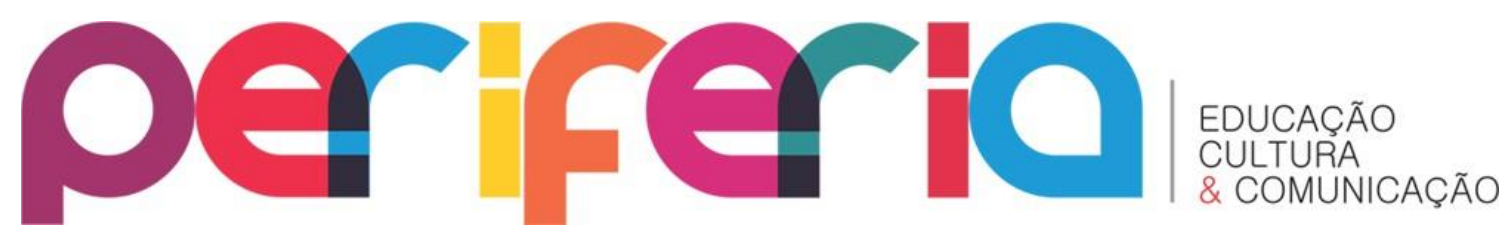

TESTA, Adriana Queiroz. Entre o canto e a caneta: oralidade, escrita e conhecimento entre os Gurani Mbya. USP: São Paulo, 2008. Disponível em: http://www.scielo.br/pdf/ep/v34n2/06.pdf Acesso em: março de 2018.

URQUIZA, Antônio Hilário Aguilera. Culturas e história dos povos indígenas em Mato Grosso do Sul. Editora UFMS: Mato Grosso do Sul, 2013.

ZEPHIRO, Katia; MARTINS, Norielem. Educação Escolar Indígena Diferenciada e interculturalidade entre os Guarani Mbya do Rio de Janeiro: o legitimo e o real. Revista Periferia. v. 7, n.1, jan./jun.2015 Disponível em: http://www.epublicacoes.uerj.br/index.php/periferia/article/view/21968/15947 Acesso em: março de 2018.

\section{Vídeo}

DOCUMENTÁRIO - UMA AULA GUARANI ETE (Parte 1) Domingos Barros Nobre. UFF: Angra dos Reis, 2009. 8min. Disponível em:

https: / /www.youtube.com/watch?v=kh6cYinLLV4 Acesso em: março de 2018. 